\title{
A medição do brand equity a partir do modelo de ressonância da marca em um hotel
}

\section{The measurement of brand equity from the brand residential model in a hotel}

\author{
Paulo Roberto Ferreira ${ }^{1}$ \\ Alessandra Duarte de Oliveira ${ }^{2}$ \\ Luiz Rodrigo Cunha Moura ${ }^{3}$ \\ Nina Rosa da Silveira Cunha ${ }^{4}$
}

\begin{abstract}
Resumo
O objetivo geral deste estudo é medir a ressonância da marca do Hotel Gran Lord a partir da perspectiva do consumidor, através da investigação sistemática dos fatores envolvidos, conforme o modelo de ressonância da marca. Além disso, identificar os componentes do modelo teórico que mais se correlacionam com a ressonância da marca. Esse é um estudo descritivo de cunho quantitativo no qual, após a realização de um pré-teste, foram aplicados um total de 303 questionários. Os blocos do modelo de ressonância da marca foram avaliados em termos de proeminência, desempenho, imagem, julgamento, sentimento e ressonância da marca. Os resultados indicam que o Hotel Gran Lord possui uma boa ressonância de marca, e a correlação que ocorre entre os blocos que foram o modelo usado na pesquisa indicam a existência das relações propostas no modelo de ressonância da marca, por meio da pirâmide de marca.
\end{abstract}

Palavras-chave: Pirâmide de ressonância da marca; brand equity; branding em hotéis.

\begin{abstract}
The overall objective of this study is to measure the resonance of the Gran Lord Hotel brand from the perspective of the consumer through the systematic investigation of the factors involved according to the brand resonance model. In addition, identify the components of the theoretical model that most correlate with the resonance of the brand. This is a quantitative descriptive study in which, after a pre-test, a total of 303 questionnaires were applied. The pillars of the brand resonance model were evaluated in terms of prominence, performance, image, judgment, feeling and brand resonance. The results indicate that the Hotel Gran Lord has a good brand resonance and the correlation that occurs between the pillars that were the model used in the research indicates the existence of the relations proposed in the brand resonance model through the brand pyramid.
\end{abstract}

Key-words: Brand resonance pyramid; brand equity; hotel's branding.

Especialista em Educação Ambiental - (SENAC/MG). Especialista em Docência Superior. (UGF)1. Especialista em MBA em Gestão de Negócios - (FEAD/MG) E-mail: paulo.vivid@ gmail.com

${ }^{2}$ Mestranda em Administração pelo Centro Universitário (UNA) E-mail: alessandra.duarte@gmail.com

${ }^{3}$ Doutorando, Mestre em Administração pela (UFMG) E-mail: luizrcmoura@gmail.com

${ }^{4}$ Doutora em Economia Aplicada (UFV) E-mail: ninarosa@ufv.br

Artigo recebido em: 03 de janeiro de 2017. Artigo aceito em 11 de dezembro de 2017. 


\section{Introdução}

A expressão brand equity aparece em alguns trabalhos já na primeira metade da década de 1980. Ganhou projeção, em 1988, quando o Marketing Science Institute dos Estados Unidos realizou um seminário específico sobre brand equity. Desde então, tem se tornado um conceito cada vez mais respeitado (VARGAS NETO, 2003).

A relevância dos estudos relacionados com a marca cresceu de importância nas últimas décadas. Conquistar uma posição destacada no mercado implica, geralmente, em esforços que devem ser direcionados para o posicionamento e a diferenciação do produto ou serviço (KELLER, 2016; BASTOS; MOURA; CHRISTINO, 2014).

Durante décadas, os pesquisadores dedicaram uma tremenda atenção na construção do valor da marca, a qual se refere à utilidade incremental ou valor agregado a um produto pela sua marca. Usando um modelo baseado na visão comportamental do consumidor, o brand equityé a resposta diferente dos consumidores entre uma marca focal e um produto sem marca, quando ambos têm o mesmo nível de estímulos de marketing e atributos do produto. A diferença na resposta do consumidor pode ser atribuída à marca e demonstra os efeitos do investimento a longo prazo no marketing da marca (YOO; DONTHU, 2001).

Artigos recentes sobre marcas indicam que o brand equity é atualmente o foco de marketing de muitas empresas líderes de mercado. Para eles, não é apenas importante para as empresas que oferecem produtos tangíveis, mas também para as organizações de serviços (BASTOS; MOURA; CHRISTINO, 2014; AZIZ; YASIN, 2010).Além disso, apesar de uma quantidade considerável de interesse, a pesquisa que identifica e tenta entender os fenômenos do brand equity, houve dificuldade porque não houve acordo quanto ao que seja brand equity e, mais importante, como ele deve ser medido (YOO; DONTHU, 2001).

O objetivo desse estudo é medir a ressonância da marca do Hotel Gran Lord a partir da perspectiva do consumidor, através da investigação sistemática dos fatores envolvidos, conforme o modelo de ressonância da marca proposto por Keller (2001). Além disso, identificar os componentes do modelo teórico que mais se correlacionam com a ressonância da marca.

Em termos teóricos, esse trabalho se justifica a partir do aprofundamento do conhecimento e medição da ressonância da marca, notadamente no setor de hotelaria. Pesquisas realizadas em bases de dados, como o banco de teses e dissertações da 


\section{FERREIRA; OLIVEIRA; MOURA; CUNHA}

CAPES (Comissão de Aperfeiçoamento de Pessoal do Nível Superior), Scielo (Scientific Electronic Library Online) e google scholar, não encontraram pesquisas sobre a ressonância de marca no Brasil e, em termos internacionais, nenhum trabalho na área de turismo ou hotelaria.

Em termos gerenciais, essa pesquisa se justifica, pois uma compreensão completa do brand equity sob o ponto de vista do cliente é essencial para que o gerenciamento da marca seja bem sucedido. Um brand equity positivo sob a perspectiva do cliente pode levar a uma maior receita, menor custo e maior lucro. Tem ainda implicações diretas na capacidade da empresa de obter preços mais altos, a disposição do cliente em procurar novos canais de distribuição, a eficácia das comunicações de marketing e o sucesso de extensões de marca e oportunidades de licenciamento (TONG; HAWLEY, 2009).

O Marketing Science Institute considera como valor de marca o que se adiciona ao produto pelo nome e que é valorizado no mercado com maiores margens de lucro ou participação. Genericamente, pode-se afirmar que o valor de uma marca é definido como resultante das atividades mercadológicas a ela relacionada e pode aumentar ou reduzir ao longo do tempo. Na perspectiva da empresa, o estudo do valor de marca ocorre para os propósitos financeiros e contábeis atrelando-se indicadores, produtividade e a tomada de decisões (TAVARES, 2008).

\section{Referencial teórico}

O referencial teórico desse estudo inicia-se com a apresentação dos conceitos de brand equity ou força da marca. Em seguida, descreve-se o modelo de brand equity baseado no consumidor, denominado modelo de ressonância da marca, desenvolvido por Keller (2001).

\subsection{Brand equity - valor de marca}

O valor da marca, na percepção do consumidor, pode ser entendido como um conjunto de significados guardados na memória e as atitudes e comportamentos que decorrem dessas associações, estendendo-se aos produtos e demais elementos do composto de marketing da marca. Para fins práticos, permite que a empresa tenha volumes ou margens maiores do que teria sem o uso da marca. Decorre da percepção das ações da empresa pelo consumidor no sentido de construir determinada marca. Em 


\section{FERREIRA; OLIVEIRA; MOURA; CUNHA}

última instância, equivalerá ao preço premium pago pelo produto, a recompensa pela lealdade à marca e a manutenção da participação no mercado (TAVARES, 2008). O brand equity é um conjunto de ativos e de passivos ligados a uma marca, ao seu nome e a um símbolo, que se adicionam ou se subtraem ao valor proporcionado por um produto ou serviço para uma empresa, e/ou para os clientes/consumidores dessa empresa (AAKER, 1998).

O brand equity pode ainda ser definido como as diferenças obtidas nas respostas dos clientes em função do seu conhecimento da marca. Essa resposta pode ser pagar um preço premium, abandonar a marca, tornar-se fiel, ter a marca como preferência, endossar a marca junto aos seus conhecidos e afins.

A conceituação do brand equity implica na distinção entre o valor da marca, concebido como uma construção intrapessoal que modera o impacto das atividades de marketing e o brand value da marca, que é o valor de venda ou substituição de uma marca (RAGGIO; LEONE, 2007).

Compreender o que os clientes desejam, o que eles procuram, é fundamental para a gestão e o desenvolvimento do brand equity. Os consumidores da atualidade estão mais exigentes e buscam por algo mais que benefícios funcionais. Eles procuram por benefícios intangíveis, tais como imagem, status, personalidade, estilo de vida, sucesso e outros fatores aos quais eles possam estar fortemente relacionados (BASTOS; MOURA; CHRISTINO, 2014). Portanto, os consumidores, na perspectiva de clientes, estão à procura de uma série de atributos que excedem os aspectos físicos e tangíveis dos produtos. Esse valor incremental de utilidade dos produtos é denominado brand equity (AZIZ; YASIN, 2010).

Uma marca possui um brand equity positivo baseado no cliente se os consumidores reagem mais favoravelmente a um produto e a forma como ele é divulgado quando a marca é identificada, do que quando não é identificada. O brand equity se reflete em comportamentos, preferências e percepções relacionados com o marketing de uma marca sendo que as mais fortes ficam com a maior receita (KELLER, 2001,1993).

As fontes do valor da marca estão baseadas nas estruturas do conhecimento dos consumidores (valor da marca baseado no consumidor) e também baseadas nos entendimentos do mercado (valor da marca baseado no mercado). O poder da marca ligado à mente dos consumidores resulta das experiências e aprendizagens relacionadas 
à marca, que o indivíduo vai acumulando ao longo do tempo (KELLER, 2001,1993).

O brand equity é um conceito multidimensional e um fenômeno complexo (YASIN; AZIZ, 2010). Vários autores propuseram vários modelos de brand equity e alguns dos modelos de brand equity estabelecidos são o modelo Aaker (AAKER, 1998); o modelo de equidade de marca baseado no Cliente (CBBE) e o modelo de ressonância de marca (KELLER, 2001); avaliador de ativos de marca pela Agência de Propaganda Young e Rubicam; e o modelo BRANDZ de força de marca pelo consultor de pesquisa de marketing, Millward Brown e WPP. Entre os mais citados estão o modelo Aaker e o modelo CBBE (KOTLER; KELLER, 2012).

\subsection{O modelo de ressonância da marca}

Considerando o modelo de ressonância de marca, a construção de uma marca forte pode ser considerada em termos de uma sequência de etapas, cada uma dependente do êxito da anterior que envolve o alcance de certos objetivos com clientes atuais e potenciais (KELLER; MACHADO, 2006). Esse modelo reforça o fato de que não há atalhos na construção de uma marca, a qual é construída a partir de uma série de etapas entrelaçadas entre si, em conjunto com a percepção dos consumidores (RAUT, 2015).

O modelo de ressonância de marca pode ser considerado como o resultado bemsucedido de quatro etapas (KELLER, 2001):

- estabelecer a identidade própria da marca;

- criar o significado apropriado da marca;

- gerar respostas positivas da marca;

- forjar relacionamento de marca com clientes que se caracterizam por uma intensa e ativa lealdade.

Essas quatro etapas são descritas a partir do quadro 1 a seguir.

\section{Quadro 1-As quatro etapas de construção do valor da marca}

\begin{tabular}{|l|l|}
\hline Etapa & Objetivo \\
\hline 1. Identificação & $\begin{array}{l}\text { Garantir que os clientes são capazes de identificar a marca e associá-lo a uma } \\
\text { determinada categoria de produto ou necessidade. O objetivo desta etapa deve, } \\
\text { portanto, criar conscientização de marca profunda e ampla. }\end{array}$ \\
\hline 2. Significado & Estabelecer o que a marca significa dentro das mentes dos clientes por \\
\hline
\end{tabular}

Revista Eletrônica Gestão e Serviços v.8, n. 2, pp. 2105-2126, Julho/Dezembro 2017. ISSN Online: 2177-7284 e-mail: regs@ metodista.br 


\section{FERREIRA; OLIVEIRA; MOURA; CUNHA}

\begin{tabular}{|l|l|}
\hline & $\begin{array}{l}\text { associações com determinadas propriedades. Os pontos de diferença sobre o } \\
\text { outro produto são benefícios ou atributos que os consumidores associam com } \\
\text { uma determinada marca e que eles acreditam que são uma característica única } \\
\text { que nenhuma outra marca possui. }\end{array}$ \\
\hline 3. Respostas & $\begin{array}{l}\text { Evocar a resposta adequada dos clientes quanto à identidade e significado da } \\
\text { marca. }\end{array}$ \\
\hline 4. Relacionamentos & $\begin{array}{l}\text { Converter a resposta da marca em uma relação de lealdade forte e ativa entre o } \\
\text { cliente e a marca. }\end{array}$ \\
\hline
\end{tabular}

Fonte: Adaptado de Adrian (2014, p.12)

A primeira etapa deste modelo é garantir a identificação da marca com os clientes e uma associação da marca na mente dos clientes com uma classe de produto específico ou necessidade do cliente. O segundo passo é estabelecer firmemente o significado da marca na mente dos clientes, vinculando estrategicamente uma série de associações de marcas tangíveis e intangíveis. O terceiro passo é obter as respostas adequadas do cliente para essa identidade de marca e significado de marca. O quarto e último passo deste modelo é a conversão da resposta da marca para criar uma relação de fidelidade intensa e ativa entre os clientes e a marca. $\mathrm{O}$ modelo fornece uma maneira abrangente de cobrir temas importantes da marca, bem como insights úteis e orientações para as empresas para ajudá-las a definir a direção estratégica e informar suas decisões relacionadas com a marca (CHOUDHURY; KAKATI, 2014).

É importante estruturar a tarefa e eles propõem o estabelecimento de seis blocos sequenciais para a construção da marca. Esses blocos podem ser apresentados sob a forma de uma pirâmide. Ainda segundo os autores, criar brand equity implica atingir o topo da pirâmide de marca do modelo CBBE (Consumer Based Brand equity). Isso somente ocorrerá se os blocos corretos forem combinados (KELLER; MACHADO, 2006).

Segundo o modelo de ressonância da marca, é preciso erguer uma pirâmide de seis blocos ou alicerces da marca. Essa pirâmide possui duas rotas: a rota racional para a construção da marca está do lado esquerdo (julgamento e desempenho) enquanto a emocional fica do lado direito (sensações e imagem) (KOTLER; KELLER, 2012).

A figura 1 apresenta as quatro etapas, bem como os seis blocos que a estruturam e suas subdimensões. A primeira etapa é representada pela base da pirâmide e a quarta etapa pelo seu topo.

Revista Eletrônica Gestão e Serviços v.8, n. 2, pp. 2105-2126, Julho/Dezembro 2017.

ISSN Online: 2177-7284 e-mail: regs@metodista.br 
Figura 1 - Pirâmide das quatro etapas do processo de construção do brand equity, os seis blocos e as suas subdimensões

\begin{tabular}{|c|c|c|c|c|}
\hline ETAPAS & \multicolumn{2}{|c|}{ OS SEIS BLOCOS } & \multicolumn{2}{|c|}{ SUBDIMENSÕES DOS BLOCOS } \\
\hline $\begin{array}{l}4 \\
\text { Relacionamentos: } \\
\text { Que relacionamento } \\
\text { quero com você? }\end{array}$ & Ressor & lância & \multicolumn{2}{|l|}{$\begin{array}{l}\text { Ressonância: } \\
\text { Fidelidade } \\
\text { Adesão } \\
\text { Engajamento }\end{array}$} \\
\hline $\begin{array}{l}3 \\
\text { Respostas: } \\
\text { O que penso de } \\
\text { você? }\end{array}$ & Julgamentos & Sensaçōes & $\begin{array}{l}\text { Julgamentos: } \\
\text { Qualidade } \\
\text { Credibilidade } \\
\text { Consideração } \\
\text { Superioridade }\end{array}$ & $\begin{array}{l}\text { Sensações: } \\
\text { Ternura } \\
\text { Diversão } \\
\text { Entusiasmo } \\
\text { Segurança } \\
\text { Aceitação } \\
\text { social } \\
\text { Autoestima }\end{array}$ \\
\hline $\begin{array}{l}2 \\
\text { Significado: } \\
\text { O que você é? }\end{array}$ & Desempenho & Imagem & $\begin{array}{l}\text { Desempenho: } \\
\text { Características } \\
\text { primárias e aspectos } \\
\text { secundários; } \\
\text { Confiabilidade, } \\
\text { durabilidade } \\
\text { e disponibilidade de } \\
\text { serviços / assistência } \\
\text { do produto; } \\
\text { Efetividade, eficiência, } \\
\text { e empatia do serviço; e } \\
\text { Estilo e design. }\end{array}$ & $\begin{array}{l}\text { Imagem: } \\
\text { Perfis dos } \\
\text { usuários; } \\
\text { Situações de } \\
\text { compra } \\
\text { e utilização; } \\
\text { Personalidad } \\
\text { e } \\
\text { e valores; } \\
\text { História, } \\
\text { legado, } \\
\text { e } \\
\text { experiências. }\end{array}$ \\
\hline $\begin{array}{l}1 \\
\text { Identificação: } \\
\text { Quem é você? }\end{array}$ & & Aencla & $\begin{array}{l}\text { Proeminência: } \\
\text { Identificação de categori } \\
\text { Necessidades satisfeitas }\end{array}$ & \\
\hline
\end{tabular}

Fonte: Adaptado de Keller (2016; 2001).

Revista Eletrônica Gestão e Serviços v.8, n. 2, pp. 2105-2126, Julho/Dezembro 2017. ISSN Online: 2177-7284 e-mail: regs@metodista.br 
O relacionamento com marca depende da experiência vivida pelos consumidores, definindo o nível de relacionamento com a marca. Os relacionamentos oferecem significados ao consumidor, sendo alguns deles funcionais e utilitários, enquanto outros são psicológicos ou emocionais (SANDHE, 2016). O processo de mover de baixo para cima da pirâmide ajuda na criação de valor ou equidade da marca de equidade. Os seis blocos de construção são (KELLER, 1993):

\subsection{A proeminência da marca}

A proeminência é o primeiro bloco da pirâmide- a base- e refere-se à profundidade (reconhecimento e recordação) e à extensão (compra e consideração de consumo) de consciência da marca (BAIRD, 2015). O consumidor deve compreender a categoria em que uma marca concorre no mercado e estar ciente das necessidades que a marca pode satisfazer para o consumidor. Isso está relacionado à consciência do consumidor sobre a marca (KELLER, 2001).

Alcançar a identidade certa da marca envolve a criação de destaque da marca (saliência ou proeminência). A notoriedade da marca está relacionada a aspectos da conscientização do cliente sobre a marca (SANDHE, 2016; GAUTAM; KUMAR, 2012). Keller (2001) aprofunda reflexão sobre esse conceito a partir das seguintes perguntas: Com que facilidade e frequência a marca é evocada em várias situações ou circunstâncias? Em que medida é a marca top-of-the-mind e facilmente recordada ou reconhecida? Que tipos de dicas ou lembretes são necessários? Quão penetrante é o reconhecimento da marca?

A consciência de marca é um aspecto muito importante e representa a habilidade de identificar a marca. Tal habilidade envolve dois elementos: o reconhecimento da marca (os consumidores conseguem discriminar corretamente a marca) e a lembrança ou recordação de marca na memória. Aumentar a consciência da marca significa aumentar também a probabilidade de ela ser considerada no processo de decisão de compra. Os consumidores tendem a criar um conjunto de marcas de sua preferência para simplificar o processo rotineiro de decisão de compra (KELLER, 2001).

O desempenho da marca

No segundo nível da pirâmide são criados os significados de marca para os 
consumidores por meio de duas etapas dentro da segunda camada da pirâmide; desempenho e imagens (KOTLER; KELLER, 2012). O desempenho da marca diz respeito a como o produto ou serviço atende às necessidades funcionais do cliente (BAIRD, 2015).

O produto em si é o cerne da marca, pois é a principal influência dos consumidores que experimentam a marca, que ouvem sobre uma marca de outros e o que a empresa pode dizer aos clientes sobre a marca em suas comunicações. Para criar fidelidade à marca e a ressonância no topo da pirâmide, a experiência dos consumidores com o produto deve pelo menos satisfazer, se não superar, suas expectativas (KELLER, 2001).

\subsection{A imagem da marca}

A imagem da marca se relaciona com os aspectos intangíveis da marca e normalmente está associada com a propaganda e o boca a boca. A imagem permite que a marca atenda às necessidades abstratas ou psicológicas dos consumidores (KOTLER; KELLER, 2012).

Em relação aos produtos, as imagens de marca tratam das suas propriedades extrínsecas, incluindo as maneiras pelas quais a marca tenta atender às necessidades psicológicas e sociais dos clientes (GAUTAM; KUMAR, 2012; KELLER, 2001).

Julgamentos da marca

A terceira camada da pirâmide inclui julgamentos e sentimentos, a fim de cumprir as respostas da marca ao consumidor. Os julgamentos são formados a partir das dimensões de desempenho e imagens, e são avaliações de clientes quanto à marca (GAUTAM; KUMAR, 2012; BAIRD, 2015).

O julgamento de um cliente é baseado em opiniões pessoais e na sua avaliação sobre a marca. Existem diferentes tipos de julgamentos, mas, para criar uma marca forte, quatro tipos requerem maior atenção: qualidade, credibilidade, relevância e superioridade (TRI, 2014):

- Qualidade de marca é o critério básico para os clientes. Qualidade de marca também significa a qualidade dos produtos e serviços. Dentro desta categoria, valor e satisfação são as dimensões mais essenciais. A qualidade da marca também pode ser determinada 


\section{FERREIRA; OLIVEIRA; MOURA; CUNHA}

objetivamente por especialistas ou pessoas que tenham entendimento sobre detalhes técnicos;

- Credibilidade da marca é a medida em que uma marca apresenta diferentes níveis de confiabilidade entre os clientes. Ela se preocupa mais com a garantia de fazer negócios com a marca. A credibilidade da marca é medida com base em três critérios principais: perícia (competência da marca), confiabilidade (sensibilidade à demanda do cliente) e atratividade;

- A consideração da marca é completamente diferente dos dois tipos de julgamentos anteriores porque depende altamente da relevância da necessidade dos clientes. A marca deve ser reconhecida como provedora de soluções;

- A superioridade da marca relaciona-se à diferenciação nas características do produto, no serviço, na política ou em qualquer coisa que possa beneficiar os clientes. No entanto, a diferenciação deve ser relevante para os clientes e ser coerente com a identidade da marca.

\subsection{Os sentimentos da marca}

São respostas e reações emocionais dos clientes com respeito à marca. Os sentimentos de marca, também se relacionam com a moeda social evocada pela marca (GAUTAM; KUMAR, 2012; KELLER, 2001).

A forma como um consumidor responde ao programa de marketing tem um grande impacto sobre obrand equity (BAIRD, 2015). Por conseguinte, de acordo com Keller (2001), "os gestores devem assegurar que a marca deve assegurar que as respostas sejam favoráveis e venha à mente quando se pensa na marca."

\subsection{Ressonância da marca}

O topo da pirâmide termina com a marca formando um relacionamento com o consumidor e esse tendo identificação pessoal com a marca (BAIRD, 2015). Esse topo, formado pela ressonância da marca é a etapa final do modelo, no qual as relações de marca focalizam o relacionamento final e o nível de identificação que o cliente tem com a marca (KOTLER; KELLER, 2012). Em suma, como resumem Gautam e Kumar (2012), significa a medida em que os clientes sentem que estão "sincronizados com a marca".

Revista Eletrônica Gestão e Serviços v.8, n. 2, pp. 2105-2126, Julho/Dezembro 2017. ISSN Online: 2177-7284 e-mail: regs@ metodista.br 


\section{FERREIRA; OLIVEIRA; MOURA; CUNHA}

Assim, é possível perceber que o modelo de ressonância da marca é uma estrutura que pode ser usada como um guia para criar relações de fidelidade ou lealdade intensas e ativas com os clientes (MÁRKUS; FALLMYR, 2014).

\section{Método}

Essa pesquisa pode ser classificada como uma pesquisa descritiva na qual se tem o objetivo de se conhecer as características de uma determinada população ou se mensurar quantitativamente diversos construtos para se checar teorias ou verificar hipóteses (MALHOTRA, 2011). Além disso, a partir da abordagem da análise de dados verifica-se que essa é uma pesquisa de cunho quantitativo.

O questionário foi elaborado considerando o modelo de ressonância da marca de acordo com os seguintes estudos anteriores, notadamente no setor financeiro de instituições bancárias (RAUT, 2015; CHOUDHUR; KAKATI, 2014; FARHANA; ISLAM, 2012; AZIZ; YASIN, 2010). Os blocos do modelo de ressonância de marca foram caracterizados e traduzidos sob a forma de perguntas fechadas.

Foram elaboradas vinte e três questões cujas respostas variavam de 0 a 10 , em escala relativa, onde 0 equivale a "Discordo plenamente", e 10, "Concordo plenamente". Além disso, apresentaram-se duas questões idênticas em locais distintos do questionário com o intuito de verificar o nível de concentração e atenção dos respondentes em relação ao preenchimento do questionário. Em relação a essas duas questões, os questionários que apresentaram uma diferença acima de dois pontos para essas duas questões foram descartados.

A amostra utilizada foi "não probabilística por conveniência", o que implicou na seleção subjetiva dos respondentes, de acordo com sua experiência e com o objetivo da pesquisa. Nesse tipo de amostra, os seus elementos são selecionados de acordo com a conveniência do pesquisador. São as pessoas que estão ao alcance e dispostas a responder o questionário de pesquisa. Essa técnica é mais simples e de menor custo (SAMARA; BARROS, 1997).

Ao aplicar o questionário de pesquisa, um critério precisou ser satisfeito na definição dos entrevistados qualificados: eles deveriam ter utilizado os serviços de hospedagem do Hotel Gran Lord pelo menos uma vez.Por esse motivo, optou-se pela aplicação dos questionários no próprio hotel e durante o período de hospedagem.

No pré-teste foi identificada uma dificuldade de conseguir hóspedes interessados 
FERREIRA; OLIVEIRA; MOURA; CUNHA

no preenchimento do questionário, alegando o tamanho do mesmo. Posteriormente, considerou-se que a aplicação no check out (saída) do hotel não era adequada. Essa constatação levou à solicitação de preenchimento em um momento no qual os hóspedes estivessem esperando ou aguardando por algum serviço. O tempo de espera no restaurante ou na recepção mostrou-se adequado para a finalidade da pesquisa e para os respondentes que preencheram sem reclamar e sem se sentirem incomodados. O número de respondentes foi de 303 pessoas, resultando em 277 questionários válidos, a partir da eliminação dos questionários com alta ocorrência de dados faltantes, bem como aqueles que apresentaram um valor maior do que dois pontos para as duas questões idênticas.

\section{Análise dos dados e resultados obtidos}

O processo de análise de dados abrange três pontos principais. Inicialmente, tem-se a caracterização da amostra com a descrição dos seus indicadores. Em seguida, são apresentados os valores relativos à análise descritiva dos itens de cada um dos seis blocos, bem como uma análise dos próprios blocos.

O terceiro item é a análise da correlação entre os blocos com o intuito de verificar as relações entre eles e a indicação ou não da existência do modelo de ressonância de marca por meio da cadeia de relações entre os seus blocos.

\subsection{Caracterização da amostra}

Em relação ao sexo, a distribuição mostrou-se bastante equilibrada, sendo que foram 113 respondentes do sexo feminino (40,7\%) e 164 do sexo masculino $(59,3 \%)$.

Outro item abordado em relação à composição da amostra é a renda familiar. Os resultados podem ser observados na tabela 1 a seguir.

Tabela 1- Perfil de renda mensal familiar dos respondentes

\begin{tabular}{lcc}
\hline \multicolumn{1}{c}{ Renda } & Frequência & $\begin{array}{c}\text { Porcentual } \\
(\%)\end{array}$ \\
\hline Até R\$ 1.760,00 (até 2 salários mínimos - S. M.) & 47 & 17,0 \\
Entre R \$ 1.761,00 até R \$ 4.400,00 (entre 2 S. M. e 5 S. M.) & 67 & 24,2 \\
Entre R\$ 4.401,00 até R \$ 7.040,00 (entre 5 S. M. e 8 S. M.) & 99 & 35,7 \\
Entre R\$ 7.041,00 até R \$ 8.800,00 (entre 8 S. M. e 10 S. M.) & 36 & 13,0 \\
Entre R\$ 8.801,00 até R\$ 13.200,00 (entre 10 S. M. e 15 S. M.) & 18 & 6,5 \\
Entre R\$ 7.965,00 até R\$ 10.136,00 (acima de15 S. M.) & 10 & 3,6 \\
\hline
\end{tabular}

Revista Eletrônica Gestão e Serviços v.8, n. 2, pp. 2105-2126, Julho/Dezembro 2017.

ISSN Online: 2177-7284 e-mail: regs@ metodista.br 
Nota: o valor do salário mínimo na época da pesquisa era de 880 reais. Optou-se por esse tipo de divisão para facilitar posteriores comparações de resultados considerando-se o número de salários mínimos que os respondentes das futuras amostras receberão.

Fonte: dados da pesquisa.

Segundo dados da Associação Brasileira de Empresas de Pesquisa (ABEP, 2014), as estimativas de renda familiar mensal para os estratos socioeconômicos (classes sociais) com valores baseados na PNAD 2013 do Instituto Brasileiro de Geografia e Estatística (IBGE) indicam a distribuição da tabela 2- Estimativa para a renda média domiciliar para os estratos do Critério Brasil (ABEP).

Tabela 2 - Estimativa para a renda média domiciliar para os estratos do Critério

\section{Brasil}

\begin{tabular}{ll}
\hline Classe & Renda mensal familiar $(\mathbf{R} \$)$ \\
\hline A & $20.272,56$ \\
B1 & $8.695,88$ \\
B2 & $4.427,36$ \\
C1 & $2.409,01$ \\
C2 & $1.446,24$ \\
D - E & 639,78 \\
\hline
\end{tabular}

Fonte: ABEP, 2014.

O perfil de distribuição da renda mensal dos participantes indica que os clientes com renda entre $\mathrm{R} \$ 1.760,00$ e $\mathrm{R} \$ 8.800$ mensais representam $76,9 \%$ do total pesquisado. Dentro deste estrato é possível verificar que pouco mais da metade $(35,7 \%)$ tem renda mensal familiar situada entre $\mathrm{R} \$ 4.401,00$ até $\mathrm{R} \$ 7.040,00$, o que pressupõe um cliente de padrão mais exigente, cujo padrão de renda familiar encaixa no estrato socioeconômico B2 evoluindo para B1, de acordo com o Critério Brasil da ABEP.

Outro item verificado em relação às características da amostra é a faixa etária dos respondentes. Analisando-se a tabela 3, verifica-se que o maior grupo possui entre 36 e 50 anos de idade, com cerca de 41,5\% do total. Em seguida, aparecem os respondentes entre 18 anos e menores de 36 anos, com 29,6\% do total. 
Tabela 3 - Idade dos respondentes

\begin{tabular}{lcc}
\hline \multicolumn{1}{c}{ Idade } & Quantidade & Participação porcentual (\%) \\
\hline Menos de 18 anos & 15,00 & 5,4 \\
Entre 18 anos e menos de 36 anos & 82,00 & 29,6 \\
Entre 36 anos e menos de 50 anos & 115,00 & 41,5 \\
Entre 50 anos e menos de 65 anos & 53,00 & 19,1 \\
65 anos ou mais & 12,00 & 4,3 \\
\hline
\end{tabular}

Fonte: dados da pesquisa.

O perfil etário da amostra tem como características ser diversificado e ao mesmo tempo maduro, o que favorece uma avaliação potencialmente mais equilibrada quanto aos construtos ligados ao significado da marca (desempenho / imagem) e respostas (julgamento / sensações).

Ainda em relação às características da amostra, o principal motivo da viagem à cidade Pará de Minas foi em função de "negócios", correspondendo a 53,3\% das respostas, sendo que pelo motivo de "lazer" foram $46,7 \%$ do total de respondentes.

\subsection{Análise descritiva}

A percepção dos respondentes em relação à ressonância de marca do Hotel Gran Lord é apresentada na tabela 4 a seguir, a qual apresenta a média da avaliação dos respondentes para cada um dos itens que formam os seus blocos do modelo de ressonância de marca (proeminência, desempenho, imagem, julgamento, sentimento e ressonância). As questões foram, então, agrupadas, considerando cada pilar na pirâmide de ressonância da marca, e a média foi novamente considerada para cada item agrupado.

Tabela 4 - Média dos itens de ressonância de marca e dos seus blocos

\begin{tabular}{clcc}
\hline $\begin{array}{c}\text { Pilar da Ressonância } \\
\text { da Marca }\end{array}$ & \multicolumn{1}{c}{ Questões } & $\begin{array}{c}\text { Média } \\
\text { dos itens }\end{array}$ & $\begin{array}{c}\text { Média do } \\
\text { Pilar }\end{array}$ \\
\hline & $\begin{array}{l}\text { Eu posso reconhecer a marca do Hotel Gran Lord } \\
\text { em relação às outras marcas de hotéis. }\end{array}$ & 7,56 \\
& $\begin{array}{l}\text { Eu posso lembrar facilmente da marca ou do } \\
\text { símbolo ou do logotipo do Hotel Gran Lord. }\end{array}$ & 7,68 \\
& A marca Gran Lord é bem fácil de ser reconhecida. & & 7,7 \\
\hline Proeminência & Em comparação com outros hotéis da mesma & & \\
\hline & $\begin{array}{l}\text { categoria em Pará de Minas, o Gran Lord oferece o } \\
\text { melhor serviço. }\end{array}$ & 7,91 & 7,96 \\
\hline
\end{tabular}

Revista Eletrônica Gestão e Serviços v.8, n. 2, pp. 2105-2126, Julho/Dezembro 2017.

ISSN Online: 2177-7284 e-mail: regs@ metodista.br 


\section{FERREIRA; OLIVEIRA; MOURA; CUNHA}

O Hotel Gran Lord atende às minhas expectativas.

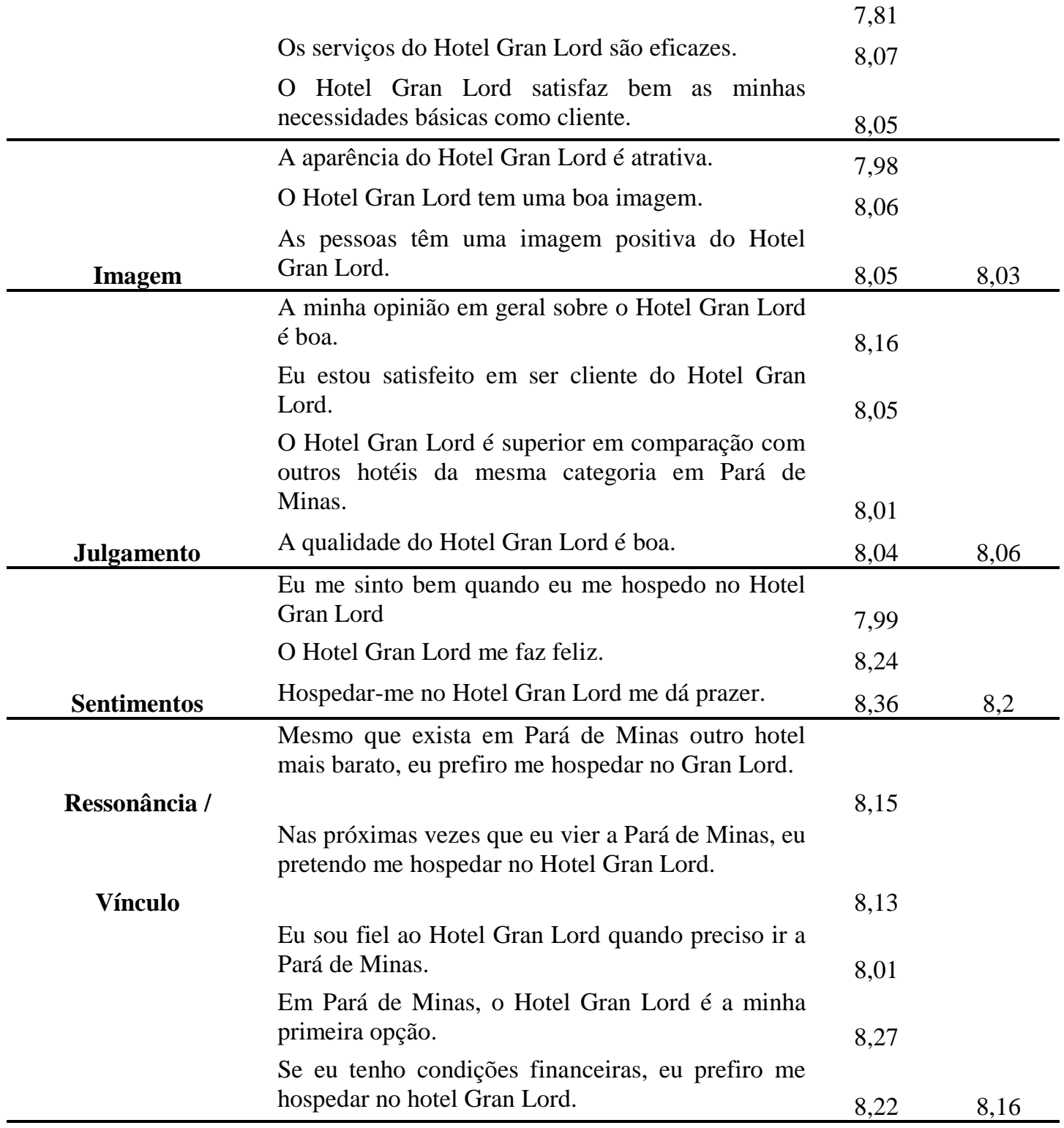

Fonte: Dados da pesquisa.

Analisando-se as respostas dos clientes do Hotel Gran Lord, é possível verificar e avaliar o posicionamento de cada pilar da ressonância da marca de acordo com as respostas relativas às perguntas do questionário. As médias podem variar entre 0 e 10 pontos.

Proeminência: quanto à proeminência, a maior média foi alcançada na resposta relativa à facilidade de reconhecimento da marca Gran Lord ("A marca Gran Lord é bem fácil de ser reconhecida") com 7,88 pontos. Os clientes afirmaram também ter relativa facilidade para se lembrarem da marca e do logotipo do Hotel. A média relativa à proeminência foi de 7,70. Acredita-se que médias superiores a 7,00 indicam uma boa 


\section{FERREIRA; OLIVEIRA; MOURA; CUNHA}

proeminência da marca. No entanto, seria interessante avaliar utilizando outros métodos de pesquisa que validem as afirmações; ou seja, a consciência e a identificação por parte dos seus clientes a respeito da marca do Hotel pode ser considerada senão boa, pelo menos positiva.

Desempenho: a percepção positiva do desempenho na execução dos serviços pode ser identificada nas duas respostas que obtiveram as maiores médias ("Os serviços do Hotel Gran Lord são eficazes", com a média foi 8,07 pontos e "O Hotel Gran Lord satisfaz bem as minhas necessidades básicas como cliente", com a média de 8,05 pontos). Além disso, a média relativa ao desempenho foi de 7,96 pontos, um valor bem próximo de 8 pontos. Trata-se de uma média positiva, mas que precisa ser melhorada, pois o desempenho é um dos blocos mais importantes na construção da ressonância da marca. O Hotel Gran Lord tem nesse pilar oportunidades de melhoria não especificadas pelos clientes. A menor média foi justamente para a questão "O Hotel Gran Lord atende às minhas expectativas", com 7,81 pontos.

Imagem: no pilar imagem, a nota média sobe para 8,03 pontos e as respostas indicam uma opinião bem homogênea por parte dos clientes, a partir das questões "a aparência do hotel é boa" com avaliação de 7,98 pontos; "o Hotel tem boa imagem" com uma pontuação de 8,06 pontos e por fim, "as pessoas tem imagem positiva do Hotel Gran Lord" com uma nota de 8,05 pontos. Em princípio, percebe-se que os clientes guardam uma imagem boa e atraente do Hotel sendo que consideram que as pessoas também têm uma imagem positiva do mesmo.

Julgamento: nesse pilar, as respostas apresentam um grande equilíbrio em todas as médias. "A opinião que os clientes têm sobre o hotel é boa",com avaliação de 8,16 pontos; "estão satisfeitos por serem clientes", com avaliação de 8,05 pontos;" consideram o Hotel superior quando comparado a outros na mesma categoria, na cidade" obteve uma nota de 8,01 pontos; e "a Qualidade do Hotel é boa", com uma pontuação média de 8,04 pontos. Quando questionados de forma direta quanto à qualidade, os clientes pontuaram de forma um pouco mais favorável do que o resultado obtido no pilar desempenho. A medida dessa variação foi pouco superior a $1,5 \%$ no valor das médias comparadas e indica uma grande homogeneidade na percepção dos hóspedes do hotel.

Sentimentos: os sentimentos do cliente são fundamentais para se estabelecer a ressonância em relação à marca. Os clientes do Hotel afirmaram "sentirem-se bem ao 
hospedar no hotel" com uma pontuação de 7,99 pontos; afirmaram que "o Hotel os faz felizes", com uma nota de 8,24 pontos; e que "sentem prazer ao se hospedarem no Hotel Gran Lord", com uma avaliação de 8,36 pontos. Nota-se que a escala é crescente em direção ao prazer de se hospedarem no Hotel. A média em patamar igual ou superior a 8,00 indica que o Hotel consegue construir sentimentos positivos que geram prazer e que certamente criam uma relação afetivo-emocional com a marca, resultando em certo grau de fidelização e desejo de retornar. Aprofundar no conhecimento dos hóspedes e nas coisas que geram sentimentos mais positivos e sensações de prazer e felicidade também pode ser positivo na construção do vínculo sócio emocional com os clientes.

Ressonância: no pilar da ressonância, a nota média alcançada foi de 8,16 pontos. Todas as questões relativas a esse pilar apresentam uma avaliação média superior a 8 pontos.O valor obtido para esses itens indica que "os clientes pretendem se hospedar no Gran Lord mesmo diante de ofertas mais baratas em Pará de Minas",comum valor médio de 8,15 pontos; manifestam “o desejo de se hospedarem novamente no hotel", com a pontuação de 8,13 pontos; expressam "fidelidade ao Hotel Gran Lord quando precisam ir a Pará de Minas", com uma nota média de 8,01 pontos; indicam "o hotel como sua primeira opção", com um valor de 8,27 pontos para a média; $\mathrm{e}^{\text {“ }}$ se tem condições financeiras preferem optar por se hospedarem no Hotel Gran Lord", com uma avaliação de 8,22 pontos.

\subsection{Correlação entre os blocos do modelo de ressonância de marca}

De acordo com os conceitos teóricos relativos ao modelo de ressonância de marca, o brand equity é formado por seis blocos, os quais se dividem no caminho racional - formado pelo desempenho e depois pelo julgamento - e no caminho emocional - formado primeiramente pela imagem e depois pelos sentimentos. Como ponto de partida, tem-se a proeminência e, como resultado, ou seja, como o brand equity, tem-se a ressonância.

Com o intuito de verificar a inter-relação entre esses componentes do modelo de ressonância de marca, calculou-se a correlação entre todos esses blocos. Os resultados estão na tabela 5 a seguir.

Tabela 5 - Correlação entre os blocos da pirâmide de ressonância de marca 


\begin{tabular}{|c|c|c|c|c|c|c|}
\hline Blocos & Proeminência & Desempenho & Imagem & Julgamento & Sentimento & Ressonância \\
\hline Proeminência & 1 & & & & & \\
\hline Desempenho &, $799(* *)$ & 1 & & & & \\
\hline Imagem &, $648(* *)$ &, $846(* *)$ & 1 & & & \\
\hline Julgamento &, $654(* *)$ &, $796(* *)$ &, $879(* *)$ & 1 & & \\
\hline Sentimento &, $668(* *)$ &, $766(* *)$ &, $825(* *)$ &, $897(* *)$ & 1 & \\
\hline Ressonância &, $648(* *)$ &, $799(* *)$ &, $803(* *)$ &, $829(* *)$ &, $843(* *)$ & 1 \\
\hline
\end{tabular}

Nota: **. Correlação estatisticamente significativa ao nível de 0.01 .

Fonte: Dados da pesquisa.

Os resultados presentes na tabela 5 apresentam correlações estatisticamente significativas para todas as relações entre os blocos do modelo de ressonância de marca, bem como mais da metade deles apresentam valores altos, ou seja, acima de 0.80 .

Mais especificamente em relação à pirâmide de ressonância da marca, como era previsto na teoria, a ressonância está mais correlacionada com o sentimento e com o julgamento. Todavia, ao contrário do que é esperado, a correlação entre o desempenho é maior para a imagem do que para o julgamento e a correlação entre a imagem e o julgamento, e o desempenho é maior do que a correlação entre a imagem e o sentimento. Além disso, no caso da proeminência, a sua correlação com o desempenho é maior do que as outras correlações, o que indica que provavelmente, no caso do Hotel Gran Lord, ela influencia mais o caminho racional do que o caminho emocional.

\section{Considerações finais}

A partir da avaliação dos blocos do modelo de ressonância de marca, e também de cada um dos seus seis blocos, é possível descrever que, em síntese, o Hotel Gran Lord tem uma marca conhecida, atende às expectativas de seus clientes e tem serviços satisfatórios, além de ter uma aparência atrativa associada a uma boa imagem, conseguindo gerar satisfação e prazer nos seus clientes e, como consequência, gerar uma ressonância de marca junto aos seus clientes por meio da sua fidelização já que o colocam como primeira opção, caso possam pagar e que até aceitam pagar um pouco mais.

No caso das contribuições gerenciais do artigo, em virtude de que o motivo da maioria dos respondentes em se hospedar foi por motivos profissionais, pode gerar o fato de que o caminho racional seja o mais importante, e, nesse caso, algumas das 


\section{FERREIRA; OLIVEIRA; MOURA; CUNHA}

prioridades da gestão devam estar relacionadas com o desempenho das atividades e dos processos que geram valor e satisfação para o cliente. Além disso, apesar da avaliação do pilar desempenho ter sido positiva, é necessário se atentar para a menor nota obtida para o item "o Hotel Gran Lord atende às minhas necessidades". Assim, pesquisas de marketing, bem como padronização de procedimentos, treinamento e avaliação contínua por parte dos hóspedes, são fatores fundamentais para melhorar a avaliação desse item. Além disso, no pilar julgamento, o item que compara o Hotel Grand Lord com os outros da mesma categoria em Pará de Minas teve a pior avaliação para esse pilar, apesar de apresentar uma nota acima de 8 pontos. Assim, atividades de inteligência de mercado para se conhecer os concorrentes do hotel na cidade de Pará de Minas, bem como melhoria na comunicação da marca junto aos possíveis clientes e ajustes no posicionamento da marca do hotel, são necessárias.

Outro ponto a ser destacado é que, em virtude do nível de fidelização no pilar ressonância, observado pelos clientes do Hotel Gran Lord, em algumas situações mais específicas, os gestores do hotel poderão praticar um preço premium, em virtude de que a avaliação da fidelidade dos seus clientes está acima de 8 pontos.

Alguns itens precisam de melhorias e isso é importante em virtude da correlação e do modelo teórico que preconiza que a ressonância de marca depende tanto dos julgamentos do seu público-alvo quanto dos seus sentimentos. Todavia, o pilar julgamento é consequência de uma avaliação positiva do desempenho das atividades e processos do hotel, bem como os sentimentos dependem da imagem que o público-alvo possui também a respeito do hotel.

Os resultados da pesquisa são bastante úteis para os gestores de marketing e de marca. Eles fornecem, por meio dos blocos de proeminência, desempenho, julgamento, imagem, sentimentos e ressonância, informações importantes tanto para o processo de tomada de decisões quanto para o acompanhamento das atividades realizadas. A partir dos resultados desse tipo de pesquisa é possível, para os gestores, acompanharem o desempenho das atividades realizadas, o nível de conhecimento sobre a marca, os sentimentos produzidos pela marca junto aos clientes, bem como o nível de fidelização dos clientes, entre vários outros itens.

Em relação às contribuições acadêmicas, pode-se destacar que essa - em princípio - é a primeira aplicação do modelo de ressonância de marca no Brasil, notadamente no setor de hotelaria. A transcrição do questionário para o português e a 


\section{FERREIRA; OLIVEIRA; MOURA; CUNHA}

sua aplicação podem ser consideradas contribuições em termos teóricos. No caso das correlações realizadas, elas indicam a possibilidade da existência do modelo de pirâmide de ressonância de marca, conforme preconizado pela teoria, em virtude do alto nível de correlação entre os blocos ou componentes desse modelo e, além disso, a validade nomológica foi alcançada.

As principais limitações desse trabalho estão relacionadas com a composição da amostra, a qual foi obtida por meio de métodos não probabilísticos, o que impossibilita a generalização dos resultados obtidos. Além disso, com a dificuldade de se obter a cooperação dos respondentes ao realizar o check-out do hotel - em virtude da pressa e da necessidade de realização de outras atividades - optou-se por aplicar o questionário no momento em que os hóspedes esperavam pelo seu pedido no restaurante do hotel. Esse fato pode influenciar a avaliação dos respondentes de modo que eles transfiram a avaliação do restaurante em grande parte na avaliação geral do hotel, tanto em termos racionais - desempenho e julgamento - quanto em termos emocionais por meio da imagem e dos sentimentos.

Em relação aos estudos futuros, mais especificamente no setor de hotelaria, poder-se-ia verificar se existem diferenças em relação aos blocos, notadamente em relação àqueles relacionados mais aos aspectos emocionais e aqueles relacionados mais aos aspectos racionais. Existem diferenças entre os hóspedes que estão viajando mais a lazer em comparação com aqueles que estão viajando por motivos profissionais, em termos da formação da ressonância da marca? Além disso, também poderiam ser realizados estudos para verificar e testar as relações presentes na cadeia nomológica representada pela pirâmide de ressonância de marca.

\section{Referências}

AAKER, D. Marcas: brand equity - gerenciando o valor da marca. São Paulo: Negócios, 1998.

ADRIAN, S. An empirical study of the car modification market. 2014. 109f. Master Thesis(Master in marketing) -Umeå School of Business and Economics, Sweden, 2014.

ABEP - ASSOCIAÇÃO BRASILEIRA DE EMPRESAS DE PESQUISAS. Critério de classificação econômica Brasil. Disponível em: <http://www.abep.org/criteriobrasil>. Acesso em: $26 \mathrm{dez} .2016$.

AZIZ, N. A.; YASIN, N. M. Analyzing the brand equity and resonance of banking

Revista Eletrônica Gestão e Serviços v.8, n. 2, pp. 2105-2126, Julho/Dezembro 2017.

ISSN Online: 2177-7284 e-mail: regs@ metodista.br 
services: Malaysian consumer perspective. International Journal of Marketing Studies, v. 2, n. 2, p. 180-189, 2010.

BAIRD, M. D. Effects of Product Prototypicality on Brand Resonance in Brand Extensions. 2015. 390f. Thesis (Doctorade in Marketing) - Curtin Business School, Bentley, 2015.

BASTOS, D. H.; MOURA, L. R. C.; CHRISTINO, J. M. M. Brand Equity da Usiminas: um estudo no setor siderúrgico brasileiro de aços planos. Gestão e Sociedade, v. 8, n. 20, p. 688-713, 2014.

CHOUDHURY, S.; KAKATI, R. P. An Analytical Study of Spillover Effect of Different Branding Elements on Customer-Based Brand Equity. IUP Journal of Brand Management, v. 11, n. 1, p. 30-46, 2014.

FARHANA, N.; ISLAM, S. Analyzing the brand equity and resonance of banking services: Bangladeshi consumer perspective. World Review of Business Research, v. 2, n. 4, p. 148-163, 2012.

GAUTAM, V.; KUMAR, M. An empirical investigation to analyze the brand equity and resonance of banking services: Evidence from India. Management, v. 7, n. 1, p. 3-16, 2012.

KELLER, K. L. Conceptualizing, measuring, and managing customer-based brand equity. Journal of Marketing, v. 57, n. 1, p. 1-22, 1993.

KELLER, K. L. Building customer-based brand equity. Marketing Management, v. 10, n. 2, p. 14-19, 2001

KELLER, K. L. Reflections on customer-based brand equity: perspectives, progress, and priorities. AMS Review, v. 6, n. 1-2, p. 1-16, 2016.

KELLER, K. L.; MACHADO, M. Gestão estratégica de marcas. São Paulo: Pearson Prentice Hall, 2006.

KOTLER, P.; KELLER, K. L. Administração de Marketing. São Paulo: Pearson Education, 2012.

MALHOTRA, N. K. Pesquisa de Marketing: uma orientação aplicada. Porto Alegre: Bookman, 2011.

MÁRKUS, A.; FALLMYR, J. Framing the Brand.2014. 110f. Master`s Thesis (Doctorade inStrategy, Organization, Leadership) -Copenhagen Business School, Copenhagen, 2014.

RAGGIO, R. D.; LEONE, R. P. The theoretical separation of brand equity and brand value: Managerial implications for strategic planning. Journal of Brand Management, v. 14, n. 5, p. 380-395, 2007. 
RAUT, U. R. Analysis of brand resonance amongst young consumers with reference to select product categories.2015. 235f. Tese (Doutorado em administração e gestão de negócios) -Universidade do Porto, Portugal, 2015.

SAMARA, B. S.; BARROS, J. C. de. Pesquisas de marketing: conceitos e metodologia. São Paulo: Makron Books, 1997.

SANDHE, A. A. An exploratory study of brand equity of a commercial bank in Vadodara, India. Independent Journal of Management \& Production, v. 7, n. 2, p. 289-302, 2016.

TAVARES, M. C. Gestão de marcas: construindo marcas de valor. São Paulo: Harbra, 2008.

TONG, X.; HAWLEY, J. M. Measuring customer-based brand equity: empirical evidence from the sportswear market in China. Journal of Product \& Brand Management, v. 18, n. 4, p. 262-271, 2009.

TRI, H. M.Branding Implementation of SMEs in Vietnam. Case: Alpine Creative Ltd.2014. 67f. Tese (Doctorade in International Business) -Saimaa University of Applied Sciences. Lappeenranta, Finland, 2014.

VARGAS NETO, A. Mensuração de brand equity baseada no consumidor: avaliação de escala multidimensional.2003. 97f. Dissertação (Mestrado em Administração) -Universidade Federal do Rio Grande do Sul, Porto Alegre, 2003.

YASIN, N. M.; AZIZ, N. A. Determinants Of Brand Equity Of Services: a verification approach in the banking industry in Malaysia. Asean Marketing Journal, v. 2, n. 2, p. 27-34, 2010.

YOO, B.; DONTHU, N. Developing and validating a multidimensional consumer-based brand equity scale. Journal of business research, v. 52, n. 1, p. 1-14, 2001. 